\title{
Association between Homa Index and Vascular Endothelial Dysfunction in Type 2 Diabetic Patients
}

\author{
N. Rama Kumari1 ${ }^{*}$, I. Bhaskara Raju², M. Aruna Devi³, M. Pallam Praveen ${ }^{2}$ \\ ${ }^{1}$ Department of Cardiology, Nizam's Institute of Medical Sciences, Hyderabad, India \\ ${ }^{2}$ Gandhi Medical College, Secunderabad, India \\ ${ }^{3}$ Department of Radiology, Nizam's Institute of Medical Sciences, Hyderabad, India \\ Email: testinet@yahoo.co.in, ${ }^{*}$ stenting@yahoo.com, dribraju@yahoo.co.in, ibrajudr@yahoo.co.in, \\ arunabilu@yahoo.co.in, pallampraveen@yahoo.com
}

Received 6 October 2014; revised 5 November 2014; accepted 28 November 2014

Copyright (C) 2014 by authors and Scientific Research Publishing Inc.

This work is licensed under the Creative Commons Attribution International License (CC BY).

http://creativecommons.org/licenses/by/4.0/

(c) (i) Open Access

\section{Abstract}

Introduction: In recent years, flow mediated dilatation (FMD) has become a popular technique in cardiovascular medicine. HOMA-IR was accepted to determine the insulin sensitivity as a valuable standard. In this study, we evaluated the association between HOMA-IR (homeostasis model assessment of insulin resistance) and vascular endothelial dysfunction, as assessed by endotheliumdependent flow-mediated dilatation (FMD) and nitroglycerin-mediated dilatation (NMD), in type 2 Diabetic (DM) patients. Material and Methods: Eighty four (84) consecutive out-patients were enrolled. HOMA-IR was calculated as fasting insulin $(\mu \mathrm{U} / \mathrm{ml})$ multiplied by fasting plasma glucose (FPG) (mg/dl) and divided by 405. The ultrasound method for measuring FMD and NMD has been used. Out of 84 patients, 42 patients were in control group and 42 patients were in diabetic group, which were further subdivided into two groups based on HOMA-IR $>3.0$ and above was considered as Group I and HOMA IR $<3.0$ and below was considered as Group II. Fasting Plasma Glucose $(\mathrm{mmol} / \mathrm{dl})(7.74 \pm 2.56,6.81 \pm 1.9, \mathrm{p}<0.001)$ and Fasting Insulin $(\mu \mathrm{U} / \mathrm{dl})(13.26 \pm 8.09,6.65 \pm 2.36, \mathrm{p}$ $<0.001$ ) were statistically significant in Group I. The baseline mean FMD in controls and cases (Group I and Group II) was 15.36 $\pm 9.56,4.15 \pm 2.29,12.21 \pm 6.24(\mathrm{p}<0.001)$ respectively. By logistic regression analysis the factors which were effective on FMD percentage change $(<5.5 \%)$ in Group I were BMI $(p<0.02)$, plasma Insulin $(p<0.04)$ and triglycerides $(p<0.02)$. There was a negative co-relation for FMD, NMD and HOMA-IR. Discussion: We conclude that increased HOMAIR in hyperglycaemic patients is associated with severe endothelial dysfunction which is the marker of the atherosclerosis. Thus the measurement of endothelial vasomotor function which is a comprehensive analysis of atherosclerotic burden may provide a better predictive value of future

\footnotetext{
"Corresponding author.
}

How to cite this paper: Kumari, N.R., Raju, I.B., Devi, M.A. and Praveen, M.P. (2014) Association between Homa Index and Vascular Endothelial Dysfunction in Type 2 Diabetic Patients. Open Journal of Internal Medicine, 4, 123-129. 
cardiovascular events than the analysis of each of the traditional risk factors alone.

\section{Keywords}

Flow Mediated Dilatation (FMD), Homeostasis Model Assessment of İnsulin Resistance (HOMA-IR), Nitroglycerin-Mediated Dilatation (NMD)

\section{Introduction}

In recent years, flow mediated dilatation (FMD) has become a popular technique in cardiovascular medicine and clinical physiology, as evidence has occurred that depressed FMD is an independent prognostic index of incident and recurrent cardiovascular events which adds predictive value to the established risk factors [1]-[5].

The FMD measurement has gained a growing interest as several studies indicate that a decreased FMD response predicts arterial disease progression with intimal thickening and increased cardiovascular mortality [6] [7]. Several cardiovascular risk factors have been shown to lead to acute and chronic FMD impairment [6] [8].

Insulin Resistance (IR) is defined as a disorder of insulin mediated glucose release. Although hyperinsulinemia itself is a marker for IR, it can also be determined using methods such as hyperglycemic-euglycemic clamp technique [9], intravenous glucose tolerance test [10] and insulin compression test [11]. Since these techniques are complicated and difficult to utilize and there are some difficulties in the daily routine usage and application to wide populations, easier indexes which depend on clinical measurements are improved. HOMA-IR is well correlated with hyperglycemic-euglycemic clamp technique [9]-[12], which was accepted to determine the insulin sensitivity as a valuable standard [13]. It has been shown that insulin has various vascular benefits, like increasing the nitric oxide (NO) activity, releasing NO synthesis gene expression [14] [15] and causing vasodilatation [16]. As it is known that insulin increases the endothelium dependent dilatation this effect is impaired with the presence of IR.

It is known that endothelial dysfunction has a close relation with hyperglycemia, hypertension, dyslipidemia, fibrinolysis, obesity and insulin resistance (IR), and has a major role in progression of micro-vascular complications [17]-[20]. In this study, we evaluated the association between HOMA-IR (homeostasis model assessment of insulin resistance) and vascular endothelial dysfunction, as assessed by endothelium-dependent flow-mediated dilatation (FMD) and nitroglycerin-mediated dilatation (NMD), in type 2 Diabetic (DM) patients.

\section{Material and Methods}

\subsection{Study Patients}

Eighty four (84) consecutive out-patients from the Department of Cardiology and endocrinology were enrolled in this study during the period of May 2013 to January 2014. Ethical committee approval and informed consent from each patient were obtained. Exclusion criteria were the presence of clinically evident micro/macro vascular complications of diabetes, i.e., the clinical or ECG evidence of CAD, past or present episodes of stroke, and/or TIA, clinical evidence of peripheral vascular disease, features suggestive of diabetic retinopathy on fundus examination, presence of overt proteinuria or serum creatinine $>2 \mathrm{mg} / \mathrm{dl}$, clinical evidence of diabetic neuropathy, associated co-morbid illness which is likely to influence the endothelial function like Smoking, alcoholism, hypertension, congestive cardiac failure, liver diseases, chronic infections, renal diseases.

\subsection{Procedural Protocol}

Clinical examination included blood pressure measurement, cardiovascular examination, and body-mass index (BMI) measurement. Biochemical assessment included fasting blood sugar (FBS), post-prandial blood sugar (PPBS) levels and comprehensive lipid profile. Plasma glucose, insulin and lipid estimation were done after an overnight fast of $12 \mathrm{~h}$. Homeostasis model assessment ratio (HOMA-IR) which was calculated as fasting insulin $(\mu \mathrm{U} / \mathrm{ml})$ multiplied by fasting plasma glucose (FPG) $(\mathrm{mg} / \mathrm{dl})$ and divided by 405 , was used to assess the insulin sensitivity in the subjects without insulin therapy. 


\subsection{Determination of Vascular Function with Ultrasound}

The ultrasound method for measuring endothelium dependent and endothelium independent arterial dilatation has been used as described previously. The brachial artery diameter was measured on B-mode ultrasound images, with the use of a $7.5 \mathrm{MHz}$ linear array transducer with image point HX Ultra sound Equipment (iE33 2-D Echo, Philips Ultrasound Bothell, Washington DC, USA). The right brachial artery was studied in all the subjects. Brachial artery endothelial function was studied after the subject had abstained from alcohol, caffeine, and smoking for 8 hours. Scans were obtained with the subject at rest, during reactive hyperaemia and again at rest. The subjects were asked to lie quietly for at least $10 \mathrm{~min}$ before the first scan. The brachial artery was scanned in longitudinal section $2 \mathrm{~cm}$ above the elbow, the centre of the artery was identified when the clearest picture of the anterior and posterior intimal layers was obtained. The transmit (focus) zone was set to the depth of the near wall, because of the greater difficulty in evaluating the " $\mathrm{M}$ " line (the interface between the media and adventitia) of the near wall as compared with that of the far wall. Depth and gain settings were set to optimize images of the interface between the lumen and the arterial wall, and the images were magnified. Settings for operating the machine were not changed during the study.

When a satisfactory transducer position was found, the skin was marked and the arm was kept in the same position throughout the study. A resting scan was obtained. The arterial diameter was measured. Increased flow was then induced by the inflation of a sphygmomanometer cuff placed around the forearm (distal to the scanned part of the artery) to a pressure of $200 \mathrm{mmHg}$ for 5 minutes followed by release. A second scan was performed continuously of 30 seconds, 60 seconds and 120 seconds after deflation of the cuff. The diameter of the artery was measured at the peak of $\mathrm{R}$ wave (Corresponding to end diastole).

Flow-mediated dilatation was calculated, and the average result of the three observations was recorded. Flowmediated dilatation results are presented as the percent change diameter post ischemia (d2)-diameter baseline (d1) divided by diameter baseline (d1) multiplied by 100 . Severe endothelial dysfunction was defined as FMD < $5.5 \%[21]$ as has been described. 15 minutes was allowed for vessel to recovery and then a further resting scan was taken, then sublingual glycerol tri nitrate (GTN-200 mics puff) was administered and 4 minutes after, the last scan was done. ECG was monitored throughout the scans and artery diameter measured at the peak of R wave (corresponding to end diastole). An average of 3 values was taken for each measurement.

\subsection{Statistical Analysis}

Statistical software: The Statistical software namely SAS 9.2, SPSS 15.0, Stata 10.1, MedCalc 9.0.1, Systat 12.0 and $\mathrm{R}$ environment ver. 2.11.1 were used.

Statistical Methods: Descriptive and inferential statistical analysis has been carried out in the present study. Results on continuous measurements are presented as mean \pm SD (min-max) and results on categorical measurements are presented in number (\%). Significance is assessed at $5 \%$ level of significance. The following assumptions on data is made: 1) Dependent variables should be normally distributed; 2) Samples drawn from the population should be random cases of the samples should be independent analysis of variance (ANOVA) has been used to find the significance of study parameters between three or more groups of patients, student $t$ test (two tailed, independent) has been used to find the significance of study parameters on continuous scale between two groups (Inter group analysis) on metric parameters. Chi-square/Fisher Exact test has been used to find the significance of study parameters on categorical scale between two or more groups. Multivariate logistic regression analysis was used to predict the FMD $<5.5 \%$ and HOMA-IR $>3.0$ using different risk factors. P value $<$ 0.05 was considered significant.

\section{Results}

In our study Eighty four (84) consecutive out-patients from the department of Cardiology and Endocrinology were enrolled in this study. The clinical characteristics were summarized in Table 1. Out of 84 patients, 42 patients were in control group and 42 patients were in diabetic group which further sub divided into two groups based on HOMA-IR $>3.0$ and more was considered as Group I and HOMA IR $<3.0$ was considered as Group II. Fasting Plasma Glucose $(\mathrm{mmol} / \mathrm{dl})(7.74 \pm 2.56,6.81 \pm 1.9, \mathrm{p}<0.001)$ and Fasting Insulin $(\mu \mathrm{U} / \mathrm{dl})(13.26 \pm$ $8.09,6.65 \pm 2.36, \mathrm{p}<0.001)$ were statistically significant in Group I. 
Table 1. Demographic data.

\begin{tabular}{|c|c|c|c|c|}
\hline & Control & Cases (Group I) & Cases (Group II) & $\mathrm{p}$ Value \\
\hline Age & $44.81 \pm 10.70$ & $50.88 \pm 9.39$ & $50.40 \pm 11.20$ & 0.049 \\
\hline BMI & $24.29 \pm 3.70$ & $27.23 \pm 4.37$ & $25.87 \pm 3.20$ & 0.019 \\
\hline HTN & $6(14.3 \%)$ & $7(41.2 \%)$ & $11(44 \%)$ & \\
\hline Smoking & $11(26.2 \%)$ & $2(11.8 \%)$ & $1(4 \%)$ & \\
\hline FHD & $2(4.8 \%)$ & $0(0 \%)$ & $1(4 \%)$ & \\
\hline $\mathrm{TC}$ & $164.31 \pm 40.61$ & $162.07 \pm 40.67$ & $176.57 \pm 27.11$ & 0.40 \\
\hline TG & $151.94 \pm 67.13$ & $163.73 \pm 52.29$ & $182.20 \pm 51.11$ & 0.20 \\
\hline LDL & $94.11 \pm 32.27$ & $99.80 \pm 26.35$ & $109.40 \pm 26.54$ & 0.19 \\
\hline HDL & $40.37 \pm 10.7$ & $37.80 \pm 8.63$ & $36.95 \pm 6.47$ & 0.37 \\
\hline Aspirin & $13(31 \%)$ & $5(29.4 \%)$ & $7(28 \%)$ & 1.00 \\
\hline Clopidogrel & $7(16.7 \%)$ & $2(11.8 \%)$ & $2(8 \%)$ & 0.701 \\
\hline Statin & $17(40.5 \%)$ & $16(94.1 \%)$ & $24(96 \%)$ & $<0.001$ \\
\hline B blockers & $18(42.9 \%)$ & $7(41.2 \%)$ & $7(28 \%)$ & 0.460 \\
\hline FBSS (mg/dl) & $5.47 \pm 0.61$ & $7.74 \pm 2.56$ & $6.81 \pm 1.89$ & $<0.001$ \\
\hline Insulin $(\mu \mathrm{U} / \mathrm{dl})$ & $11.58 \pm 6.38$ & $13.26 \pm 8.09$ & $6.65 \pm 2.36$ & $<0.001$ \\
\hline Homa-IR & $2.50 \pm 1.25$ & $4.98 \pm 2.23$ & $1.85 \pm 0.56$ & $<0.001$ \\
\hline
\end{tabular}

The baseline mean FMD in controls and cases (Group I and Group II) was $15.36 \pm 9.56,4.15 \pm 2.29,12.21 \pm$ $6.24(\mathrm{p}<0.001)$, mean NMD was $22.49 \pm 11.79,8.97 \pm 4.52,18.72 \pm 8.84(\mathrm{p}<0.001)$ respectively. The percentage change at the baseline and the reactive hyperaemia phase, NMD were statistically significant in both the groups (Figure 1).

By logistic regression analysis (Table 2$)$ the factors which were effective on FMD percentage change $(<5.5 \%)$ in Group I were BMI $(p<0.02)$, plasma Insulin $(p<0.04)$ and triglycerides $(p<0.02)$. In Figure 2 there was a negative co-relation for FMD, NMD and HOMA-IR for the cases.

\section{Discussion}

In our study the mean age and body mass index of diabetic patients were significantly higher than controls but there was no difference between the 2 groups. There was no statistically significant difference between the cases and controls with other risk factors like hypertension, smoking and dyslipidemia. The fasting insulin levels were significantly higher in hyperglycaemic patients with high HOMA-IR levels than the controls. Among the various factors studied fasting plasma glucose, fasting insulin and triglycerides were significant in a positive manner with FMD in Group I patients, since it was suggested that TG might provide an index for insulin resistance [21] [22].

There was a negative correlation with impaired FMD and high HOMA-IR. Similar results were observed in a study done by Krabag et al. [23]. These data suggested that poor glycemic control or insulin resistance was associated with the development of endothelial dysfunction in diabetic patients. Impaired FMD of brachial artery which is mainly caused by the loss of endothelium-derived nitric oxide has been established as a relevant marker for endothelial dysfunction. Our study showed that increased HOMA-IR was associated with impaired FMD which is a marker for endothelium injury but not NMD (marker of vascular smooth muscle function). Endothelial functional status is not determined solely by the individual risk factor burden, but rather may be regarded as an integrated index of atherogenic and athero-protective as well as unknown variables.

We conclude that increased HOMA-IR in hyperglycaemic patients is associated with severe endothelial dysfunction which is the marker of the atherosclerosis. Thus the measurement of endothelial vasomotor function 

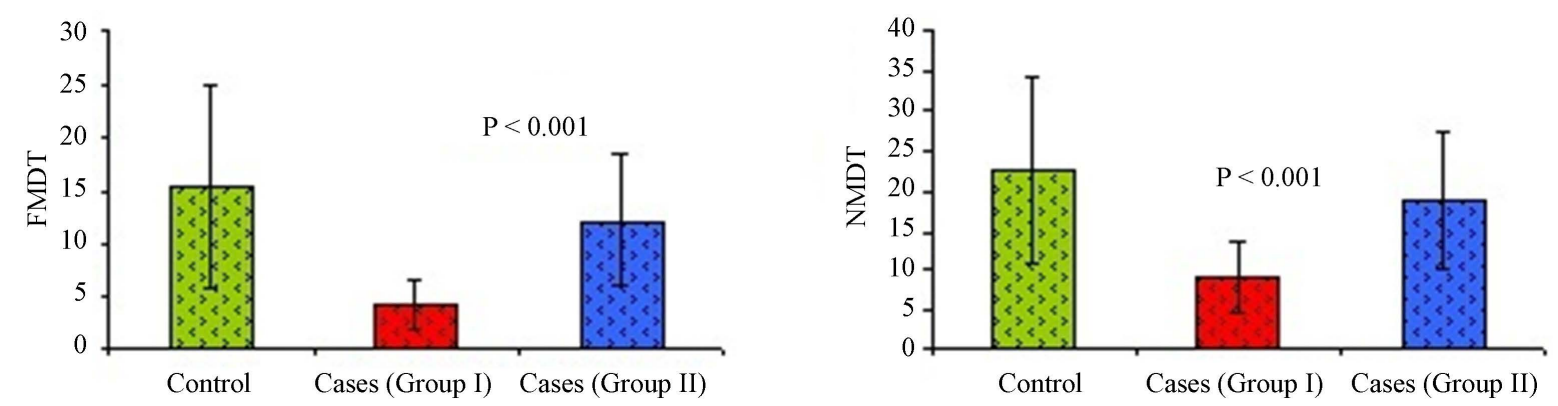

Figure 1. Comparison of groups with controls considering endothelium dependent dilation percentages.

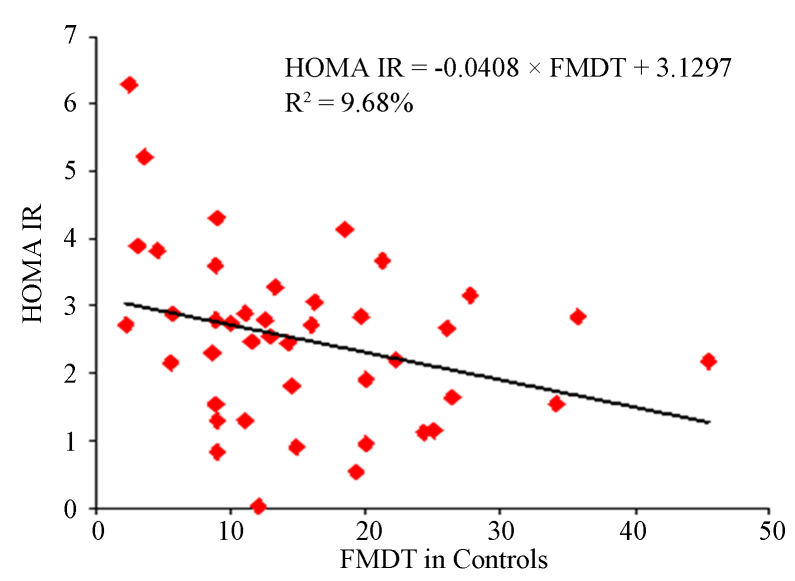

(a)

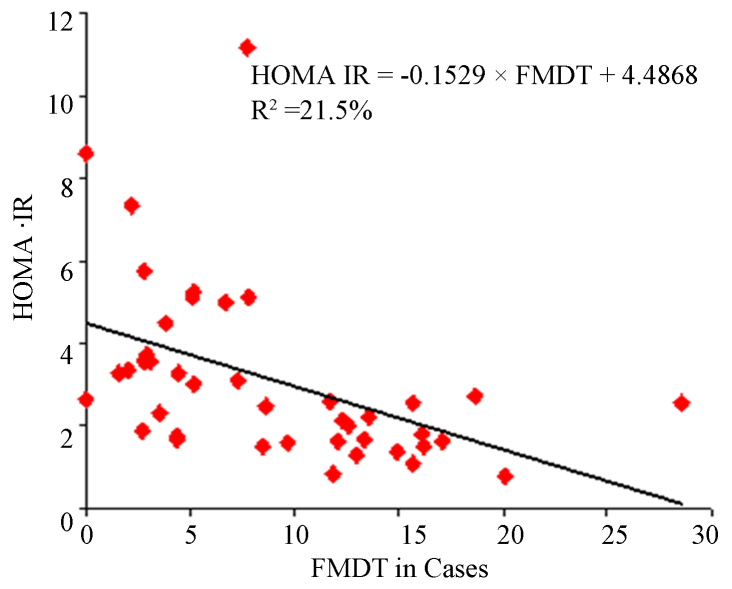

(b)

Figure 2. Logistic regression correlation analysis to predict the FMD $<5.5 \%$ and HOMA IR in (a) FMD controls and (b) FMD Cases.

Table 2. Multivariate logistic regression analysis to predict FMD $<5.5 \%$ and HOMA-IR $>3.0$.

\begin{tabular}{|c|c|c|c|c|c|}
\hline Variables & Logistic Coefficient & $\mathrm{SE}$ & $\mathrm{p}$ Value & OR & $95 \% \mathrm{CI}$ \\
\hline Age in years $(>50)$ & 0.46 & 0.92 & 0.622 & 1.58 & $0.26-9.62$ \\
\hline Gender: male & 0.34 & 0.82 & 0.677 & 1.41 & $0.28-7.09$ \\
\hline $\operatorname{BMI}\left(>25 \mathrm{~kg} / \mathrm{m}^{2}\right)$ & 2.05 & 0.86 & 0.018 & 7.75 & $1.43-42.11$ \\
\hline $\mathrm{DM}$ & 0.00 & 1.63 & 0.998 & 1.00 & $0.04-24.66$ \\
\hline HTN & -0.07 & 1.16 & 0.954 & 0.94 & $0.10-9.10$ \\
\hline Smoking & -0.26 & 1.29 & 0.837 & 0.77 & $0.06-9.54$ \\
\hline $\mathrm{F} / \mathrm{h} \mathrm{CAD}$ & -0.52 & 1.93 & 0.789 & 0.60 & $0.01-26.42$ \\
\hline Aspirin & -0.75 & 1.28 & 0.556 & 0.47 & $0.04-5.78$ \\
\hline Clopidogrel & 1.66 & 1.50 & 0.267 & 5.28 & $0.28-99.94$ \\
\hline Statins & 2.26 & 1.71 & 0.187 & 9.57 & $0.33-273.78$ \\
\hline$\beta$ blockers & -0.53 & 1.05 & 0.617 & 0.59 & $0.07-4.66$ \\
\hline FBSS (mmol/dl) & 0.19 & 0.21 & 0.381 & 1.21 & $0.79-1.83$ \\
\hline Plasma insulin $(\mu \mathrm{U} / \mathrm{dl})$ & 0.15 & 0.07 & 0.046 & 1.16 & $1.00-1.34$ \\
\hline Total cholesterol (mg/dl) & 0.01 & 0.02 & 0.392 & 1.01 & $0.98-1.05$ \\
\hline Triglycerides (mg/dl) & -0.02 & 0.01 & 0.029 & 0.98 & $0.96-1.00$ \\
\hline $\mathrm{LDL}(\mathrm{mg} / \mathrm{dl})$ & 0.00 & 0.02 & 0.843 & 1.00 & $0.96-1.03$ \\
\hline HDL (mg/dl) & -0.07 & 0.05 & 0.164 & 0.93 & $0.84-1.03$ \\
\hline
\end{tabular}


which is a comprehensive analysis of atherosclerotic burden may provide a better predictive value of future cardiovascular events than the analysis of each of the traditional risk factors alone.

\section{Conflict of Interest}

None declared.

\section{References}

[1] Gokce, N., Keaney Jr., J.F., Hunter, L.M., Watkins, M.T., Nedeljkovic, Z.S., Menzoian, J.O. and Vita, J.A. (2003) Predictive Value of Noninvasively Determined Endothelial Dysfunction for Long-Term Cardiovascular Events in Patients with Peripheral Vascular Disease. Journal of the American College of Cardiology, 41, 1769-1775. http://dx.doi.org/10.1016/S0735-1097(03)00333-4

[2] Karatzis, E.N., Ikonomidis, I., Vamvakou, G.D., Papaioannou, T.G., Protogerou, A.D., Andreadou, I., Voidonikola, P.T., Karatzi, K.N., Papamichael, C.M. and Lekakis, J.P. (2006) Long-Term Prognostic Role of Flow-Mediated Dilatation of the Brachial Artery after Acute Coronary Syndromes without ST Elevation. American Journal of Cardiology, 98, 1424-1428. http://dx.doi.org/10.1016/j.amjcard.2006.06.043

[3] Rossi, R., Nuzzo, A., Origliani, G. and Modena, M.G. (2008) Prognostic Role of Flow-Mediated Dilation and Cardiac Risk Factors in Post-Menopausal Women. Journal of the American College of Cardiology, 51, 997-1002. http://dx.doi.org/10.1016/j.jacc.2007.11.044

[4] Shechter, M., Issachar, A., Marai, I., Koren-Morag, N., Freinark, D., Shahar, Y., Shechter, A. and Feinberg, M.S. (2009) Long-Term Association of Brachial Artery Flow-Mediated Vasodilation and Cardiovascular Events in Middle-Aged Subjects with No Apparent Heart Disease. International Journal of Cardiology, 134, 52-58. http://dx.doi.org/10.1016/j.ijcard.2008.01.021

[5] Yeboah, J., Folsom, A.R., Burke, G.L., Johnson, C., Polak, J.F., Post, W., Lima, J.A., Crouse, J.R. and Herrington, D.M. (2009) Predictive Value of Brachial Flow-Mediated Dilation for Incident Cardiovascular Events in a Population-Based Study: The Multi-Ethnic Study of Atherosclerosis. Circulation, 120, 502-509.

[6] Widlansky, M.E., Gokce, N., Keaney Jr., J.F. and Vita, J.A. (2003) The Clinical Implications of Endothelial Dysfunction. Journal of the American College of Cardiology, 42, 1149-1160. http://dx.doi.org/10.1016/S0735-1097(03)00994-X

[7] Halcox, J.P., Donald, A.E., Ellins, E., Witte, D.R., Shipley, M.J., Brunner, E.J., Marmot, M.G. and Deanfield, J.E. (2009) Endothelial Function Predicts Progression of Carotid Intima-Media Thickness. Circulation, 119, 1005-1012. http://dx.doi.org/10.1161/CIRCULATIONAHA.108.765701

[8] Kelm, M. (2002) Flow-Mediated Dilatation in Human Circulation: Diagnostic and Therapeutic Aspects. American Journal of Physiology - Heart and Circulatory Physiology, 282, H1-H5.

[9] Defronzo, R.A., Tobin, J.D. and Andres, R. (1979) Glucose Clamp Technique: A Method for Quantifying Insulin Secretion and Resistance. American Journal of Physiology, 237, 214-223.

[10] Pacini, G. and Bergman, R.N. (1986) MINMOD: A Computer Program to Calculate Insulin Sensitivity and Pancreatic Responsivity from the Frequently Sampled Intravenous Glucose Tolerance Test. Computer Methods and Programs in Biomedicine, 23, 113-122. http://dx.doi.org/10.1016/0169-2607(86)90106-9

[11] Shen, S.W., Reaven, G.M. and Farquhar, J.W. (1970) Comparison of Impedance to Insulin Mediated Glucose Uptake in Normal Subjects and in Subjects with Latent Diabetes. Journal of Clinical Investigation, 49, 2151-2160. http://dx.doi.org/10.1172/JCI106433

[12] Korytkowski, M.T., Berga, S.L. and Horwitz, M.J. (1995) Comparison of the Minimal Model and the Hyperglycaemic Clamp for Measuring Insulin Sensitivity and Acute Insulin Response to Glucose. Metabolism, 44, 1121-1125. http://dx.doi.org/10.1016/0026-0495(95)90003-9

[13] Matthews, D.R., Hosker, J.P., Rudenski, A.S., et al. (1985) Homeostasis Model Assessment: Insulin Resistance and Beta-Cell Function from Fasting Plasma Glucose and Insulin Concentrations in Man. Diabetologia, 28, 412-419. http://dx.doi.org/10.1007/BF00280883

[14] Zeng, G., Nystrom, F.H., Ravichandran, L.V., et al. (2000) Roles for Insulin Receptor, P13 Kinase, and Akt in Insulin-Signalling Pathways Related to Production of Nitric Oxide in Human Vascular Endothelial Cells. Circulation, 101, 1539-1545. http://dx.doi.org/10.1161/01.CIR.101.13.1539

[15] Kuboki, K., Jiang, Z.Y., Takahara, N., et al. (2000) Regulation of Endothelial Constitutive Nitric Oxide Synthase Gene Expression in Endothelial Cells and in Vivo: A Specific Vascular Action of Insulin. Circulation, 101, 676-681. http://dx.doi.org/10.1161/01.CIR.101.6.676

[16] Cardillo, C., Kilcoyne, C.M., Nambi, S.S., et al. (1998) Vasodilator Response to Systemic but Not to Local Hyperinsu- 
linemia in the Human Forearm. Hypertension, 32, 740-745. http://dx.doi.org/10.1161/01.HYP.32.4.740

[17] Ross, R. (1999) Atherosclerosis-An Inflammatory Disease. American Heart Journal, 138, 419-420. http://dx.doi.org/10.1016/S0002-8703(99)70266-8

[18] Steinberg, H.O., Chaker, H., Leaming, R., et al. (1996) Obesity/Insulin Resistance Is Associated with Endothelial Dysfunction. Implications for the Syndrome of Insulin Resistance. The American Society for Clinical Investigation, 97, 2601-2610. http://dx.doi.org/10.1172/JCI118709

[19] Tooke, J.E. (1995) Micro Vascular Function in Human Diabetes: A Physiologic Perspective. Diabetes, 44, 721-726. http://dx.doi.org/10.2337/diab.44.7.721

[20] King, G.L. and Wakasaki, H. (1992) Theoretical Mechanisms by Which Hyperglycaemia and Insulin Resistance Could Cause Cardiovascular Diseases in Diabetes. Diabetes Care, 22, 31-37.

[21] Kitta, Y., Obata, J., Nakamura, T., et al. (2009) Persistent Impairment of Endothelial Vasomotor Function Has a Negative Impact on Outcome in Patients with Coronary Artery Disease. Journal of the American College of Cardiology, 53, 323-330. http://dx.doi.org/10.1016/j.jacc.2008.08.074

[22] Yoda, K., Inaba, M., Hamamata, K., Yoda, M., et al. (2014) Association between Glycemic Control and Morning Blood Pressure Surge with Vascular Endothelial Dysfunction in Type 2 Diabetic Patients. Diabetes Care, 37, 644-650. http://dx.doi.org/10.2337/dc13-1102

[23] Karabag, T., Kaya, A., Yavuz, S., et al. (2007) The Relation of HOMA Index with Endothelial Functions Determined by Flow Mediated Dilatation Method among Hyperglcemic Patients. Indian Heart Journal, 59, 463-467. 
Scientific Research Publishing (SCIRP) is one of the largest Open Access journal publishers. It is currently publishing more than 200 open access, online, peer-reviewed journals covering a wide range of academic disciplines. SCIRP serves the worldwide academic communities and contributes to the progress and application of science with its publication.

Other selected journals from SCIRP are listed as below. Submit your manuscript to us via either submit@scirp.org or Online Submission Portal.
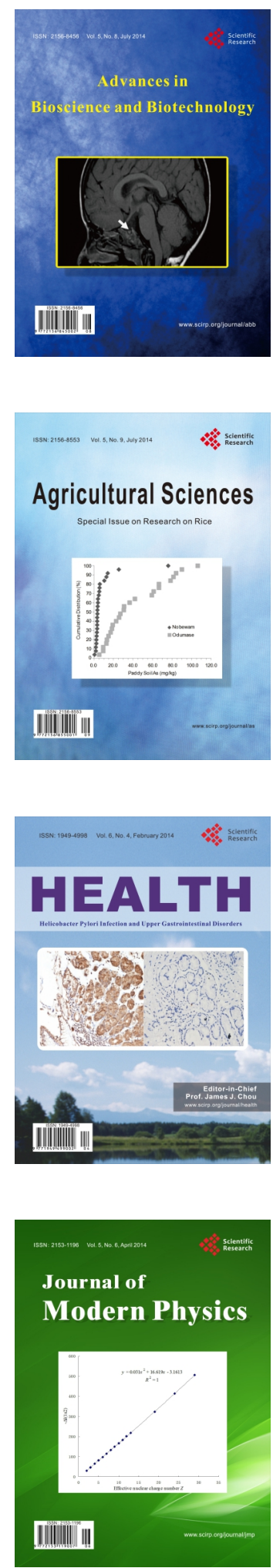
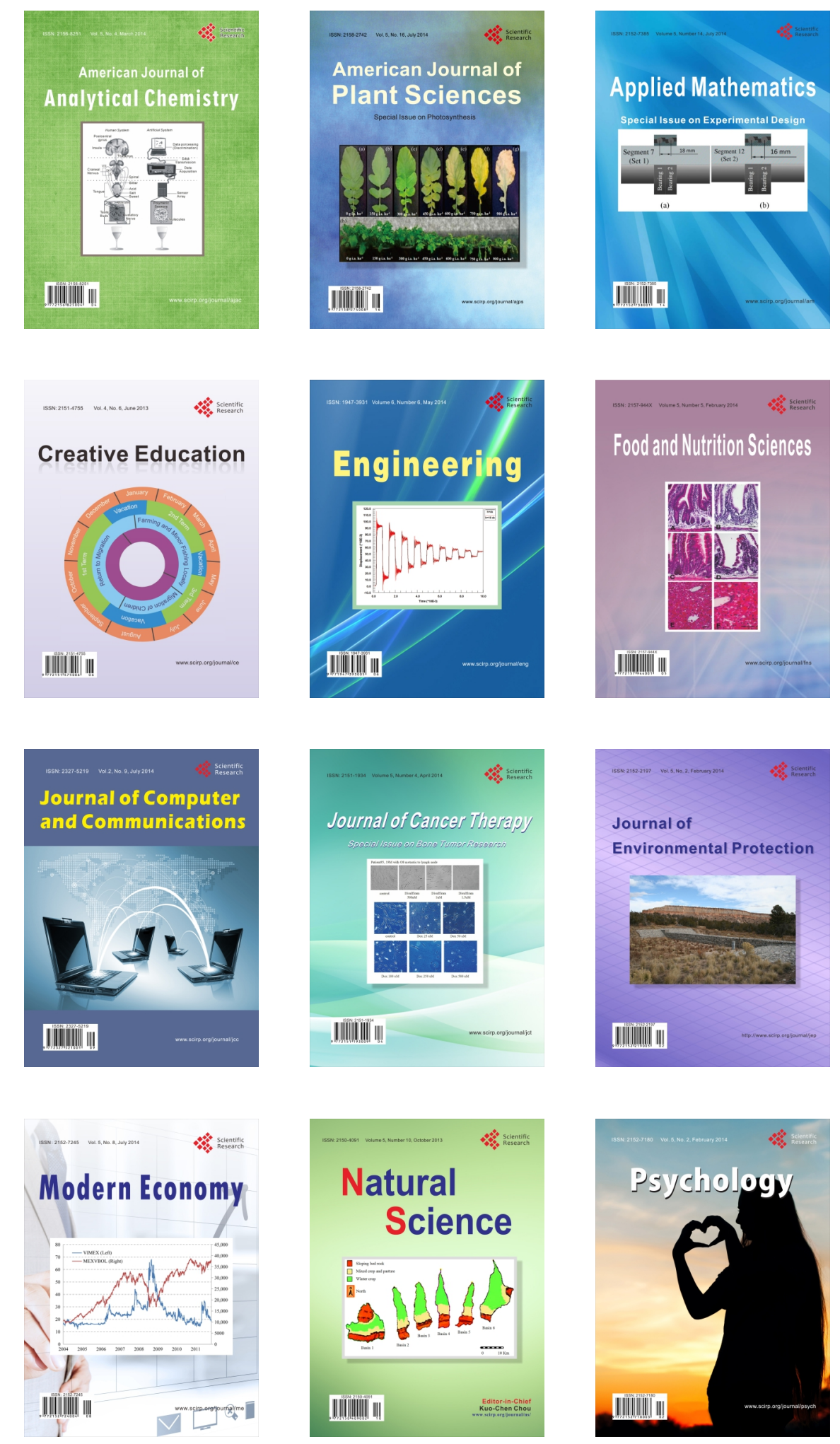